\title{
Increasing Inclusive Education Through a Learning Center Model: A California Approach
}

\author{
Aja McKee ${ }^{1} \&$ Audri Sandoval Gomez ${ }^{2}$ \\ ${ }^{1}$ College of Education, Department of Special Education, California State University, Fullerton, California, USA \\ ${ }^{2}$ Attallah College of Educational Studies, Thompson Policy Institute on DisAbility, Chapman University, \\ California, USA \\ Correspondence: Aja McKee, College of Education, California State University, Fullerton, California, USA. Tel: \\ 194-9289-1530. E-mail: amckee@fullerton.edu
}

Received: January 31, 2020

Accepted: February 20, 2020

Online Published: March 24, 2020

doi:10.20849/jed.v4i1.705

URL: https://doi.org/10.20849/jed.v4i1.705

\begin{abstract}
Learning center models offer students with disabilities learning experiences in general education classrooms, while retaining support and services from special education personnel. The learning center approach examines existing educational perspectives, practices and structures, surrounding access to general education for students with disabilities. This study used a document analysis, a qualitative data method, to examine how two California school districts developed a learning center model to transform special education programming from segregated special education classrooms and practices to placement and access to general education. The findings inform educational programming for students with disabilities in the least restrictive environment, to comply with the American federal mandate. Findings suggest that the deep structure of educational practices complicated the ease of a change in practices for both general and special educators. However, the community approach of the learning center model, where all teachers assume the educational responsibilities for all students, forced these educators to be flexible, reexamine structures and practices, and challenge the ethos of traditional schooling.
\end{abstract}

Keywords: collaboration, inclusive education, special education, least restrictive environment

\section{Introduction}

With decades of research demonstrating the benefits of inclusive education (Allen \& Slee, 2008; Causton-Theoharis, Theoharis, Cosier, \& Orsati, 2011; Cosier \& Ashby, 2016; Danforth, 2014; Daniel \& King, 1997; Mastropieri et al., 1998; Waldron \& McLeskey, 1998), our current educational system continues to foster the practice of segregation based on disability. Educational practices tend to focus on the medical model of disability (Valle \& Connor, 2011), which concentrates on the impairment and deficits of an individual in an effort to develop an educational plan that will remediate these deficits or normalize the individual as much as possible. These practices have created further segregation for students with disabilities (SWD), specifically those with significant disabilities, at alarming rates (Cosier, Cardinal, \& Gomez, 2018). In an effort to provide a more inclusive education for SWD, two California school districts developed learning center models (LCMs), which provided students the ability to receive special education services in the least restrictive environment (LRE) possible. This study seeks to examine the development of these LCMs which lends to in inclusive education for SWD within the two districts.

\section{Literature Review}

Inclusion or inclusive education is not defined in the law; therefore, it has been interpreted in a variety of ways within the literature. Based on a review of the literature, inclusion or inclusive education is when SWD (a) attend the same schools as their neighbors and peers without disabilities (Obiakor, Harris, Mutua, Rotatori, \& Algozzine, 2012; Sailor \& Skrtic, 1995); (b) are accepted, have a sense of belonging, and are a part of the community (Pearpoint \& Forest, 1992) with zero-rejection and heterogeneous grouping (Sailor \& Skrtic, 1995); (c) are provided equitable educational opportunities and support (Lipsky \& Gartner, 1996); and (d) are full participants in all aspects of schooling (Loreman, Deppeler, \& Harvey, 2010).

The philosophy of inclusion is based on the LRE requirement within 1990 Individuals with Disabilities Education Act (IDEA). IDEA is American legislation governing the education for students with disabilities. The 
IDEA mandates students who are eligible to receive special education services be educated in the LRE from a continuum of educational services. LRE regulations state:

To the maximum extent appropriate, children with disabilities, including children in public or private institutions or other care facilities, are educated with children who are not disabled, and special classes, separate schooling, or other removal of children with disabilities from the regular educational environment occurs only when the nature or severity of the disability of a child is such that education in regular classes with the use of supplementary aids and services cannot be achieved satisfactorily. $§ 300.114$

The assumption of LRE was and has been that SWD could have access to general education environments; however, there are no specific guidelines for the implementation of LRE. School teams are left to interpret this mandate based on student needs and supports, which has allowed for educational segregation to continue.

Although some may argue that the IDEA mandates LRE for SWD, Ashby and Cosier (2016) argued that the continuum of services special educators use to establish LRE is not always followed, citing court cases such as Daniel R. R. v. State Board of Education (1989). Oftentimes, IEP teams recommend more restrictive environments for SWD without first trying to service the student in the general education environment with supplemental aids and services. In an effort to move away from this practice of making more restrictive recommendations without first exhausting general education placement, the LCM demands a change of perspective and a change in educational practices. Students with disabilities are considered general education students first. Services and supports for SWD must then be decided upon and provided in the general education setting before it is determined that the student needs to move outside the general education class. This perspective enables all students a sense of belonging in general education, and SWD can remain at their home school and receive equitable educational opportunities and supports. The LCM provides a space where all students and teachers work and learn collaboratively.

In fact, Cosier and Ashby (2016) substantiate that special education is a service and not a location, meaning that services for SWD can take place in any environment. This is notable because it sheds insight into the movement of special education services, and the need for not just placement and location-based discussions, but for general educators to be trained on how to best work with SWD. General education teachers are not often provided with the training and supports they need to understand how to service SWD in general education settings (Berry, 2011; Kosko \& Wilkins, 2009; Shaffer \& Thomas-Brown, 2015). There are various ways in which this can be addressed, with professional development as key to moving towards inclusive reform (Cosier, 2016). Professional development has the ability to provide educators with theoretical and practical knowledge of inclusion. This is important because Cosier (2016) argued, "If teachers do not understand the deeply rooted social oppressions and civil rights perspective of why we need more inclusive schools, they may be more likely to revert to segregated service delivery models (p. 309). In order for inclusive education to be sustainable, educators must understand practical strategies on how to include SWD in the LRE, but also believe inclusion is a right and that all children deserve an equitable education in the LRE.

Students with disabilities have had less opportunities to be educated in general education classrooms. Students with severe disabilities are more frequently educated in segregated environments and away from their peers without disabilities (Morningstar, Kurth, \& Kozleski, 2014). Particularly in California, access to general education classrooms for students with disabilities has varied based on severity of disability (Cosier, Sandoval Gomez, Cardinal, \& Brophy, 2020). Most recently, proposed California State A.B. 1914 (2020) recommends, “...increasing opportunities for pupils with disabilities to meaningfully participate in general education.” This legislature provides guidance on why and how inclusive education could be increased, while the programming itself will be left to each district within the state. One way in which schools in California have increased their inclusive practices is through the development and implementation of the LCM.

The purpose of this study was to examine how two California school districts moved from self-contained special education programming models to an LCM approach, resulting in an exponential increase of access to general education for SWD. With the onset of the LCM model, the students in the self-contained, separate special education classrooms in these respective schools, were placed within general education classrooms. This allowed all students to be identified as general education students having access to general education environments. This came with the expectation that students who identified with having a disability would require explicit programming, support, and services to ensure their unique needs were being met in order to remain compliant with the Individualized Education Program (IEP).

This process of the LCM required consistent and ongoing collaboration, planning, professional development, and coaching. The research questions addressed in this study included: 
(a) How did the learning center model change (if at all) the teachers' pedagogical practices in teaching students with disabilities?

(b) How do programmatic changes to the delivery of special education services impact teachers' perceptions (i.e., attitude, viewpoint, impression)?

Through the accumulation and examination of documents (e.g., internal communication, professional development presentations, anecdotal records, assessment records, planning meeting documents, agendas, annual reports, and surveys) over the course of 15 months, school leaders and staff identified the successes and barriers in developing and implementing the LCM to promote inclusive schooling. In conducting a thorough and systematic document analysis, the researchers gained insight on how these school districts made programmatic changes to increase access to general education for SWD.

\section{Method}

\subsection{Research Design}

In this qualitative research study, document analysis was conducted by reviewing and analyzing documents developed during the initial stage and implementation of LCMs in California two school districts, across seven elementary schools. Document analysis allowed for these data to purposefully be analyzed and interpreted to develop an understanding of this shift in educational practices. This systematic procedure was applicable in understanding this single phenomenon (Bowen, 2009).

\subsection{Participants and Sampling Procedures}

Purposeful sampling was conducted to obtain participation of districts that were undergoing work in developing and executing a LCM approach to their educational programming. Criteria for the districts included schools that were in the initial planning phases of developing LCMs or that had recently begun development of LCMs within the past two years. One district, with a population of 22,000 K-12 students, was in the first year of implementing a LCM at one of the elementary school sites, which was being established as a pilot site. The second district, with a population of 34,000 students, was in the process of implementing LCMs at six of their elementary schools, all which were established within the last two years. These seven elementary school sites across the two districts were examined in this research. Each LCM site included general and special education teachers, general and special education administration, paraeducators, as well as special education teachers on special assignment (TOSAs).

\subsection{Data Collection}

Document collection spanned the course of 15 months. Once receiving Institutional Review Board (IRB) approval, all documents relating to the LCM were collected and analyzed. During the development and implementation of the LCMs, school districts created new organizational structures and implemented professional development trainings which resulted in a significant number of documents that were included in this analysis. Additionally, meetings to discuss the development of the LCMs, as well as the ongoing support provided to staff involved with LCMs, were documented. These primary sources took on various forms (e.g., internal communication, professional development presentations, anecdotal records, assessment records, planning meeting documents, agendas, annual reports, and surveys) and were compiled in an effort to undergo document analysis (McMillan, 2000). The documents were descriptive in nature, serving the purpose of explaining a current event happening in educational planning and programming (Best \& Kahn, 2003) in order to best meet the IDEA LRE mandate.

\subsection{Data Analysis}

Document analysis has become an increasingly used method and provides researchers the opportunity to delve deep into materials (Bogdan \& Knopp-Biklen, 2016). Further, document analysis provides data-rich material that highlights "how the people who produced the materials think about their world" (Bogdan \& Knopp-Biklen, 2016, p. 132). For this research study, once data were collected, Tesch's (1990) 8-step coding process was used to develop categories of the data. These categories were developed into a conceptual map to provide a visual. Last, a narrative was written for each category, highlighting the results of the study.

\section{Results}

Results of this study suggest that the LCM did have an effect on teachers' pedagogical practices and their perceptions on teaching SWD. The findings were categorized under three themes: (a) Finding the Grey; (b) Reexamining Structures and Practices; and (c) Challenging the Ethos of Traditional Schooling. Further description of each theme is provided in the following section. 


\subsection{Finding the Grey}

The theme Finding the Grey ascribed to the notion that LCM practices were not concrete in planning or application. Additionally, the theme speaks to educators and administrators, acknowledging the importance of flexibility in approach. This theme was twofold: (a) flexibility in approach to working with SWD, including programming and implementation of practices; and (b) examining behavior through an alternative lens.

The flexibility of the LCM compelled teachers to be adaptable in their approach to providing accessible instruction while meeting the legal responsibilities outlined in IEPs. This model required teachers to be responsive to the needs of students, which highlighted their desire to view educationally related needs in a black or white manner. As student needs changed over the course of the academic year, teachers needed to adjust their teaching and instruction to meet new demands, which at times posed challenges. One teacher explained, "I have to constantly be aware of [students'] perceptual, physical, and emotional needs ... there are a lot of moving parts in my class." Another teacher shared:

When it comes to academic needs it is extremely difficult for me to meet students' needs that are more than two grade levels below my class . . . as the SAI [specialized academic instruction] teacher sees and pulls my students every day, we collaborate a lot more to discuss the needs of my students.

Finding the Grey in the LCM required consistent collaboration between the general and special education teachers. Collaboration between these teachers provided varying levels of expertise to meet a wide range of needs, especially for students who are academically far behind.

Providing instruction accessible to a range of learners was reflected in discussion, specifically surrounding modified work. Teachers demonstrated a need to understand how and when to modify student work, as well as when to introduce functional curriculum. Discerning when the appropriate time to move a student from grade-level curriculum to modified curriculum was a struggle for special and general educators alike. One special educator shared, "While students can still access grade-level content, there are still large gaps in the students' knowledge." Although special educators expressed difficulty making the decisions to move students to modified work, general education teachers felt supported and experienced success in making curricular accommodations and modifications when provided with the support of their special education colleagues. With the increased collaboration between general and special educators within the LCM model, students' academic needs were being met in the general education classrooms.

In addition to struggling with the idea of moving students to modified curriculum, student behaviors posed a barrier to successful inclusion. Understanding that behavior, oftentimes considered "maladaptive," derives from preconceived notions of what is acceptable and unacceptable behavior in a classroom setting; this notion provides educators an opportunity to view their students' behavior from a position that highlights that the problem does not lie within the child, but rather the environment and situation surrounding the child (Orsati, 2016). Examining behavior through a lens other than a traditionalist behaviorist lens can help educators learn how behavior is socially constructed.

The issue of taking a traditionalist approach with behavior is problematic in two ways. First, staff mentioned that when a student with a disability was not a good fit in the general education classroom, the student spent a significant amount of time by themselves, where if the student was in a self-contained classroom, the student would be with a group. Second, one psychologist noted, "Self-contained classrooms are becoming a dumping center for behaviors." These ideas conflict in the sense that school staff believe students will benefit if grouped together based on the commonality of having a disability or sameness of needs and/or abilities. However, staff also acknowledged that segregated settings end up as a place where students with perceived maladaptive behaviors often land, which is not the objective of the special education system. The importance of this dilemma cannot be overlooked. Educators are under pressure to address anything that undermines instruction, and behavior deemed unacceptable for classrooms aligns with this category.

\subsection{Reexamining Structures and Practices}

The theme Reexamining Structures and Practices is defined as a need for current practices to be evaluated and critically examined. These practices include: (a) a need for additional time for collaborating and planning for instruction (b) a need for professional development and ongoing coaching; and (c) accepting and understanding how to provide academic access and grade students with more significant needs. Within the current structures and practices, data reflected these barriers, which are in need of reform.

4.2.1 Time Is of the Essence

A need for additional time arose throughout the data. This time was needed for collaborating and planning for 
instruction. When working with students identified as having significant support needs, special educators were unsure of what to do when the students were unable to do the work their general education counterparts were doing, but they also did not demonstrate a need for modified work. Special educators were confused as to how much time students needed for push in services (where the special educator and staff work with the student in the general education setting) versus pull out services (where the student goes to a separate room or area to work with the special educator and special education staff). One teacher shared, "What happens when students have overlapping characteristics? Students with similar needs may end up in different places." This quote signifies the teachers' uncertainty about recommending services (e.g., restrictiveness, setting) resulting in placement recommendations. One way to address this concern is to provide the special and general educators time to discuss students, their needs, and how and where these needs are best met.

Educators frequently reported that time is needed to plan instruction for learners of varying abilities and for staffing, such as scheduling student services and instructional assistants. In fact, educators and principals discussed professional learning communities (PLCs), sharing that while the district provided time for planning, PLC time often did not apply to this type of planning. In some schools, special and general educators did not plan together. Special educators felt as though the PLCs on their campus were not applicable, meaning the time did not address the needs or approaches needed to work with SWD. This prompted groups of special educators to form PLC groups districtwide (e.g., mild/moderate and moderate/severe groupings) to plan with others who had similar groups of students they served. The idea to take from this is that PLC time must incorporate this type of work. When PLC time does not address instructional planning for all students, SWD are left by the wayside, and general and special educators are unprepared to work with SWD in a cohesive manner in the general education setting. In addition to planning time, educators and other school staff stated a need for training. Discussion of professional development and ongoing coaching was seen as a key component to making the LCM successful.

\subsubsection{A Need for Professional Development and Ongoing Coaching}

A need for professional development, including ongoing coaching arose. Professional development is an opportunity for teachers to continually learn and expand their knowledge base in the field of education.

The theme of professional development and ongoing coaching was prevalent in the feedback from educators and administrators involved in the LCMs. Coaching and feedback in the moment are critical, and although some schools provided teachers schoolwide professional development, there is a need for direct coaching and technical support where issues or concerns can be addressed and worked through with educators in real-time. One administrator expressed how the timeliness of feedback was key in his efforts to support and coach his staff with the implementation of LCMs. Another administrator commented on how he restructured his PLCs to support the LCM: "PD in the form of PLC between [special education] teachers' and learning center teachers is great to discuss best practices." The increase of collaboration and planning time allowed teachers to enhance their practices and successfully teach students with a variety of unique needs.

As part of the LCM, both school districts, across a total of seven schools, had Teachers on Special Assignment (TOSAs) who worked with special and general educators on a variety of identified needs, however, the data showed that providing only verbal feedback was not always successful in developing the skillset of teachers working in these environments. Input from staff surveys and anecdotal records indicated that demonstration and providing hands-on support was most successful in developing one's practice. One teacher commented that one of the biggest challenges faced at her school site was obtaining training that she felt was relevant for both the general and special educators, "I have many years of experience with students with academic, behavioral, and social needs. However, I have not had much training specifically for [SWD] and their specific needs or severity of their needs." Another teacher stated, "General education teachers are now practicing special education teachers, without the training." Based on the input from the teachers, there must be an authentic effort to provide ongoing professional development and coaching to ensure successful teaching practices and implementation of LCMs.

\subsubsection{Accepting and Understanding How to Provide Access and Grade Students With More Significant Needs}

The findings from this study demonstrate how the LCM assisted in altering teachers' perceptions and practices regarding where and how SWD need to be educated, regardless of their perceived significance of disability. In fact, educators frequently commented on the increase of support from their counterparts in providing instruction that was appropriate and meaningful and that met the needs of all students. One teacher explained, "I feel the learning center model is improving my experience working with a range of students . . under this model, I feel students are getting the extra help they need." As teachers' instructional practices evolved, SWD were becoming more successful with the core curriculum. For example, students demonstrated higher growth in their reading 
scores within the LCM than when they were in segregated special education classrooms.

Teachers began to take notice of these benefits of LCMs. One teacher shared, "I am relieved to know that my student, who may be receiving services next year, will be in good hands as the special education team and I work together to support them." The increased collaboration between general and special education teachers challenged the dominant notion that specific teachers were qualified to teach specific students and opened up the ability of all educators to understand and accept students who were considered "more impacted."

In addition, grading for students with a wide variety of needs posed a challenge. One school staff asked, "Should grading should be done by grade level, or based on student ability?" This comment sparked discussion on best practices for grading and report cards. One of the documents used in the analysis provided grading guidelines. The grading guidelines existed prior to the implementation of the LCMs and outlined if students' grades should reflect a given accommodation and whether notations should be made on the report card. Likewise, the same document outlined modifications, stating that, if a student does engage in modified curriculum, it must be delineated on the students' IEP and that the students' grades reflect that a modification had been made to the general education curriculum. Last, teachers were unsure who the responsible party was for determining and giving the grade (special educator or general education). The point to take from this is even though the document outlining best practices for grading existed prior to implementation of the LCM, there was still confusion on the best practices of grading for SWD. With more students included in general education than before, both general and special educators were confused with grading, making this a barrier to inclusive education.

\subsection{Challenging the Ethos of Traditional Schooling}

The LCM approach challenged the beliefs of traditional schooling in the sense that SWD must be educated by special education teachers in special education classrooms. The LCM model supported the notion that all students should be educated with one another with the proper supports and services to meet the needs of each learner. As general education teachers were broadening their skillset in providing curriculum that was more universally designed for students with a variety of needs, special education teachers realized their approach to individualization for all special education students was a concept that needed to be reexamined. Instead of providing a separate curriculum to "individualize" for SWD, the same curriculum was being used for all students, but the supports and accommodations differed based on student need. The potential barriers to accessing the curriculum was examined, and general and special educators worked alongside one another to develop strategies and approaches to ensure all students could successfully access the curriculum. Since SWD were primarily in the general education classroom, the learning center space developed into a location that allowed for any student to receive extra support when needed. This space also allowed for teachers to split up their class and have small learning groups when general and special education teachers worked collaboratively. Therefore, this space was not viewed as the special education classroom, but as an additional class on campuses that was used by many students and teachers.

These changes of practices allowed general and special educators to collaborate and no longer work in silos. However, reshaping the notion that general education can be for students with and without disabilities is challenging because segregation has been ingrained within the educational structure. One teacher commented, "Students that are capable to be in a general education class benefit from being in my class for the majority of the day and are able to work in small groups with the [special education teacher]." However, this teacher also reported:

General education is not a setting for all students. Some students are struggling in class. I have a student that cries almost every day, because she is so aware of how below grade level she is, and this is not the right environment for her.

Reexamining the situation to decipher whether the student struggling is due to the lack of curriculum accommodation, academic and behavioral support, or appropriate delivery of instruction is typically overlooked, as the behavior and deficits of the students become the focus, which typically results in a change of educational placement to a more restrictive, oftentimes segregated setting.

It is important to note that despite teachers successfully educating students with all abilities, some teachers expressed that there is a need for alternate location and programming for students with moderate to severe disabilities. Nevertheless, since all students were educated with one another, the distribution of SWD, specifically those with moderate and severe needs, across several general education teachers allowed for authentic proportionality, meaningful participation with neurotypical developing peers, and an equitable workload for teachers. 


\section{Discussion}

The findings from this study are significant, as they provide insight into teachers' perception of educating SWD to inform the practical knowledge of making inclusive practices successful using an LCM approach. The LCM allowed for general and special education teachers to collaboratively provide accessible instruction while meeting IEP requirements to ensure the success of SWD in the general education classroom. This model forced educators to acknowledge the need of a flexible approach to meet the "moving parts" of their work. This can be seen in the educators' exploration of curriculum and discussion of when to move students to a modified curriculum. This barrier to inclusive education has long existed and is known as "modification dilemma" (Bacon, 2016; Bacon \& Ferri, 2013). Bacon (2016) explained this dilemma:

The ideology being perpetuated [from this state-level policy maker] reveals a rigid understanding of curriculum that assumes that children who progress nonlinearly through grade-level curriculum do not deserve to be included in general education classrooms. This logic has resulted in many districts creating new tracks of self-contained classes for students with disabilities who cannot keep up with the pace of general education classes or who presumably need modifications on course work. (pp. 50-51)

Understanding when to move a student to modified curriculum is not easy. Not only is it challenging to know when a student is unable to access the curriculum due to difficulty with content as opposed to the way in which the curriculum is presented, but this movement to modified work can tap into an educators' feelings of "belonging." When SWD are unable to keep pace with their able-bodied peers, educators may feel SWD do not belong and should be with other students who work at the same level or pace. Modified curriculum within the LCM model would consist of the same content, but the student output may differ from their typically developing peers. Capturing the content while making the curriculum accessible is key to student success, and educators may need to be trained on how to do this type of work. Professional development should focus on addressing this obstacle so that educators have a better understanding of what warrants a move to modified curriculum and how to work through feelings of belonging regardless of perceived ability. In addition to the challenge of making curriculum accessible for all students, student behavior can significantly impact students' success in general education.

Although there is increased research in positive behavioral interventions and supports (Horner \& Sugai, 2015), and districts have increased personnel designated specifically for behavioral supports, behavioral challenges are still cited as an ongoing reason SWD are unable to be included in general education settings (Causton-Theoharis et al., 2011). School personnel develop classroom behavioral expectations and strategies, and when students do not fall within these expectations, they often are viewed as the "problem." In other words, the obstacle becomes the student. This results in students not "fitting in" to the general education classroom and oftentimes being recommended by the IEP team to move to a more restrictive environment such as a special education self-contained classroom.

The development and implementation of the LCMs allowed both general and special education teachers to work collaboratively to plan and teach students of all ability levels in the general education setting (Causton \& Tracy-Bronston, 2015; Cosier \& Ashby, 2016). With varied expertise, this collaboration changed how teachers delivered core content to meet the unique needs of all learners in the classroom. As a result, communication and collaboration increased between educators, and the confidence of general education teachers improved as they felt they had the necessary supports and strategies to teach SWD in their classroom. Causton and Tracy-Bronston (2015) highlight the importance of collaboration by arguing that, when special and general educators work together, they demonstrate increased creativity, develop meaningful support systems and experiences for students, and encourage humanistic behavior supports and positive relationships with students. This finding is notable because, although collaboration is deemed important, minimal time is dedicated to working together to support SWD. Although both districts in this study implemented PLCs, they were focused on other types of work, resulting in teachers to segregate themselves from their counterparts to find meaning in that dedicated time.

General and special education teachers began to shift in their beliefs that SWD should only be educated in the special education classroom with individualized instruction. However, there was continued belief by some teachers that there is a need for alternate locations and programming for students with moderate to severe disabilities because of the intensity of their educational and behavioral needs. There was a belief that the LCM was ideal for a specific learning profile, one less impacted by their disability. Furthermore, many teachers perceived this model to only be effective when given time to collaborate with one another and with the appropriate supports in educating SWDs in inclusive environments. 


\section{Limitations}

There are several limitations in this study including the generalizability due to the small sample size, the limited time in which data were collected, and schools differing in how they approached and implemented LCMs. Additionally, researcher bias must be addressed.

First, this study included seven schools across two school districts implementing LCMs at the time the documentation was collected. All seven schools were elementary schools, limiting the results further to this specific population of students. Second, data were used from a 15-month period, providing a limited scope on the development of LCMs and their outcomes. Having data from a longer period of time would provide an opportunity to conduct a more comprehensive analysis. A third limitation is the approach and implementation of LCMs differ between school sites. Although there is an underlying foundation of LCMs, each school is unique in its own culture and community they serve. In fact, in this study one district was a decentralized district, which played a significant role in the development and implementation of the LCMs, as this model allowed school sites increased independence with more autonomy than schools may receive in a centralized district. Further, having one district that is centralized and one that is decentralized results in differences in the organization of the districts and how programming may be conducted.

Last, both researchers worked at the respective districts included in the study and were involved in either the development and/or implementation of the study. The researchers' involvement in the districts and their role in LCM development and implementation may have elicited bias. The researchers were privy to information to which they may not have otherwise had access given their work roles at the time. However, the role of the researchers within the districts also brings an increased level of understanding of the districts' organization, functioning, and practices, which benefits the research by producing increased depth and analysis in these results.

\section{Implications}

Special education has become a place or location where SWD are educated as opposed to a service provided to SWD. Increasing inclusive education disrupts the traditional structures of schooling in how and where SWD should be educated. Furthermore, the lack of technical support, training, and education, for both general and special education teachers, hinders teachers' skills in working collaboratively to provide SWD a comprehensive, rigorous education with appropriate supports necessary to develop successful inclusive practices.

In an effort to increase inclusive learning centers, all teachers must assume the educational needs for all students. Teachers and support staff must work together in a collaborative, community approach in which the presumption of competence is assumed for all students. The way in which prospective and practicing teachers are trained must be examined. The implications from this study call for suggested future research, specifically related to training in teacher preparation programs and the ongoing education and training of teachers. Learning centers require a foundational knowledge base of educating students with diverse learning profiles. Therefore, to successfully implement an LCM, future research should address how teacher preparation programs are training all pre-service educators to teach SWD and students with diverse learning needs. Furthermore, future research should examine how ongoing training is provided to current teachers in an effort to have inclusive practices. Efforts made to investigate professional learning for pre-service and in-service teachers can support the development of greater inclusion in the classroom.

\section{Conclusion}

Given the diversity in today's schools, general education teachers will encounter students with unique educational needs. The LCM approach allows for both general and special education teachers to work collaboratively on a consistent basis and provide appropriate curriculum for students with a range of needs. This flexible approach challenges the deep structure of schooling by creating a community approach within a school setting where all teachers assume the role and responsibility for all students. This approach negates the notion of special education and general education silos and disability hierarchy. Further, the approach challenges the current teacher preparation programs and school districts to reevaluate preservice training and in-service professional development for all educators.

\section{Acknowledgements}

Thank you to the two California school districts that participated in this research study. Your participation enables other districts to learn from your work and experience. 


\section{References}

Allan, J., \& Slee, R. (2008). Doing inclusive education research. In S. L. Gabel, \& S. Danforth (Eds.), Disability $\&$ the politics of education: An international reader (pp. 141-159). New York, NY: Peter Lang.

Ashby, C., \& Cosier, M. (2016). The work and history of special education. In M. Cosier, \& C. Ashby (Eds.), Enacting change from within: Disability studies meets teaching and teacher education (pp. 21-38). New York, NY: Peter Lang.

Bacon, J. K. (2016). Navigating assessment: Understanding students through a disability studies lens. In M. Cosier, \& C. Ashby (Eds.), Enacting change from within: Disability studies meets teaching and teacher education (pp. 39-60). New York, NY: Peter Lang.

Bacon, J. K., \& Ferri, B. (2013). The impact of standards-based reform: Applying Brantlinger's critique of "hierarchical ideologies". International Journal of Inclusive Education, 17, 1312-1325. https://doi.org/10.1080/13603116.2013.826290

Berry, R. A. W. (2011). Voices of experience: general education teachers on teaching students with disabilities. International Journal of Inclusive Education, 15(6), 627-648. https://doi.org/10.1080/13603110903278035

Best, J. W., \& Kahn, J. V. (2003). Research in education (9th ed.). Boston, MA: Pearson.

Bogdan, R. C., \& Knopp-Biklen, S. (2016). Qualitative research for education: An introduction to theories and methods. New York, NY: Pearson.

Bowen, G. A. (2009). Document analysis as a qualitative research method. Qualitative Research Journal, 9(2), $1-14$.

Causton, J., \& Tracy-Brontson, C. P. (2015). The educator's handbook for inclusive school practices. Baltimore, MD: Brookes.

Causton-Theoharis, J., Theoharis, G., Cosier, M., \& Orsati, F. (2011). Does self-contained special education deliver on its promises? A critical inquiry into research and practice. Journal of Special Education Leadership, 24, 61-78. Retrieved from http://www.casecec.org/resources/jsel.asp

Cosier, M., \& Ashby, C. (2016). Enacting change from within: Disability studies meets teaching and teacher education. New York, NY: Peter Lang.

Cosier, M. (2016). Professional Development in inclusive school reform. In M. Cosier, \& C. Ashby (Eds.), Enacting change from within: Disability studies meets teaching and teacher education (pp. 295-313). New York, NY: Peter Lang.

Cosier, M., \& Ashby, C. (2016). Disability studies and the "work" of educators. In M. Cosier, \& C. Ashby (Eds.), Enacting change from within: Disability studies meets teaching and teacher education (pp. 21-38). New York, NY: Peter Lang.

Cosier, M., Cardinal, D., \& Gomez, A. (2018). A brief report: The state of inclusion and exclusion of students with disabilities in California school districts. Presentation at the Thompson Policy Institute on Disability, DisAbility Summit 2018, Orange, CA.

Cosier, M., Sandoval Gomez, A., \& Cardinal, D., \& Brophy, S. (2020). Placement of students with extensive support needs in California school districts: The state of inclusion and exclusion. International Electronic Journal of Elementary Education, 12(3), 249-255.

Danforth, S. (2014). Becoming a great inclusive educator. New York, NY: Peter Lang.

Daniel, L. G., \& King, D. A. (1997). Impact of inclusion education on academic achievement, student behavior, and self-esteem, and parental attitudes. Journal of Educational Research, 91, 67-80. https://doi.org/10.1080/00220679700597524

Horner, R. H., \& Sugai, G. (2015). School-wide PBIS: An example of applied behavior analysis implemented at a scale of social importance. Behavioral Analysis in Practice, 8, 80-85. https://doi.org/10.1007/s40617-015-0045-4

Kosko, K. W., \& Wilkins, J. L. M. (2009). General educators' in-service training and their self-perceived ability to adapt instruction for students with IEPs. Professional Educator, 33(2), 1-10.

Lipsky, D., \& Gartner, A. (1996). Equity requires inclusion: The future for all students with disabilities. In C. Christensen, \& F. Rizvi (Eds.), Disability and the dilemmas of education and justice (pp. 145-155). Buckingham, England: Open University Press. 
Loreman, T., Deppeler, J., \& Harvey, D. (2010). Inclusive education: Supporting diversity in the classroom. New York, NY: Routledge.

Mastropieri, M. A., Scruggs, T. E., Mantzicopoulos, P., Sturgeon, A., Goodwin, L., \& Chung, S. (1998). A place where living things effect and depend on each other: Qualitative and quantitative outcomes associated with

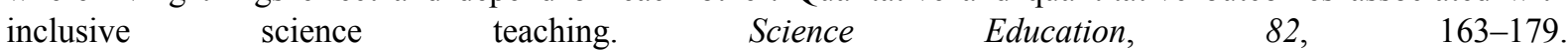
https://doi.org/10.1002/\%28SICI\%291098-237X\%28199804\%2982\%3A2<163\%3A\%3AAID-SCE3>3.0.CO\%3 B2-C

McMillan, J. H. (2000). Educational research: Fundamentals for the consumer. Boston, MA: Longman.

Morningstar, M., Kurth, J., \& Kozleski, E. (2014). The persistence of restrictive placements for students with low-incidence disabilities. Research and Practice for Persons With Severe Disabilities, 39, 227-239. https://doi.org/10.1177/1540796914555580

Obiakor, F. E., Harris, M., Mutua, K., Rotatori, A., \& Algozzine, B. (2012). Making inclusion work in general education classrooms. Education and Treatment of Children, 35, 477-490. https://doi.org/10.1353/etc.2012.0020

Orsati, F. (2016). Humanistic practices to understand and support students' behaviors: A disability studies in education framework. In M. Cosier, \& C. Ashby (Eds.), Enacting change from within: Disability studies meets teaching and teacher education (pp. 131-152). New York, NY: Peter Lang.

Pearpoint, J., \& Forest, M. (1992). Forward. In S. Stainback, \& W. Stainback (Eds.), Curriculum considerations in inclusive classrooms: Facilitating learning for all students (pp. xv-xviii). Baltimore, MD: Paul. H. Brookes.

Sailor, W., \& Skrtic, T. (1995). American education in the postmodern era. In J. L. Paul, H. Rosselli, \& D. Evans (Eds.), Integrating school structuring and special education reform (pp. 418-432). Fort Worth, TX: Harcourt Brace.

Shaffer, L., \& Thomas, B. K. (2015). Enhancing teacher competency through co-teaching and embedded professional development. Journal of Education and Training Studies, 3(3), 117-125.

Tesch, R. (1990). Qualitative research: Analysis types and software tools. New York, NY: Falmer.

Valle, J. W., \& Connor, D. J. (2011). Rethinking disability: A disability studies approach to inclusive practices. New York, NY: McGraw-Hill.

Waldron, N. L., \& McLeskey, J. (1998). The effects of an inclusive school program of students with mild and severe learning disabilities. Exceptional Children, 64, 395-405. https://doi.org/10.1177/001440299806400308

\section{Copyrights}

Copyright for this article is retained by the author(s), with first publication rights granted to the journal.

This is an open-access article distributed under the terms and conditions of the Creative Commons Attribution license (http://creativecommons.org/licenses/by/4.0/). 